\title{
Editorial
}

\section{Science in Times of COVID-19: Remembering to Tread the Side Paths}

\author{
Anna Felnhofer ${ }^{1} \&$ Oswald D. Kothgassner ${ }^{2}$ \\ ${ }^{1}$ Department of Pediatrics and Adolescent Medicine, Medical University of Vienna \\ ${ }^{2}$ Department of Child and Adolescent Psychiatry, Medical University of Vienna
}

DOI 10.24989/dp.v1i2.1932

It is all but a trivial endeavor to edit a journal issue in the midst of turmoil such as the one created by the incessant COVID-19 crisis - all the more if the journal is new and still growing. Like other periodicals, we were tempted to dedicate an entire issue to the topic, postponing already accepted non-COVID-19 papers to a later date. Yet, after careful deliberation, we decided against pursuing a whole special issue on COVID-19 and instead chose to include a special topic within a regular one. This is why:

The measures taken to contain SARS-CoV-2 - including large-scale lockdowns - have affected the lives of millions of people worldwide and have disrupted social and economic development as well as scientific enterprise (Myers et al., 2020). Since the proclamation of the pandemic by the WHO in March 2020, COVID-19 research activities have experienced an unparalleled rise, reflected not only in the vast increase of corresponding publications (Abbas \& Pittet, 2020), but also in the extraordinary number of trials related to SARS-CoV-2 or COVID-19 which were registered on ClinicalTrials.gov (Estrada, 2020). In a similar vein, the scientific landscape witnessed an increase in provision of open access articles, expedited ethical approvals, expanded third party-funding, and an upsurge of pre-print papers (Glasziou, Sanders, \& Hoffmann, 2020). While the context of crisis may produce a number of advantages (e.g., improved access to papers, reduction of bureaucratic hurdles), the recent developments seem to have led to an exacerbation of already existing pitfalls in the scientific system. Generally, these may be characterized by two phenomena, which - not just at this point in time - may be regarded as problematic for science: speed and exclusivity.

Rushing to publish studies deemed critical is not a novel phenomenon. Records reaching back to the Spanish flu at the beginning of the $20^{\text {th }}$ century describe the pressure to test treatments, resulting in an abundance of poorly conducted studies and excessive media coverage of doubtful cures (Estrada, 2020). The renowned problem of methodologically poor studies - with estimates going up as high as $85 \%$ (Glasziou, Sanders, \& Hoffmann, 2020) - has only been aggravated by the current COVID-19 crisis and is mirrored in a paucity of randomized-control-tri-

\section{Table of Contents}

1 Editorial

3 Towards a Common Framework for Mediated Embodiment

Laura Aymerich-Franch

13 Development of a Multidimensional App-Quality Assessment Tool for Health-Related Apps (AQUA)

Teresa O’Rourke, Rüdiger C. Pryss, Winfried Schlee \& Thomas Probst

24 Editorial Special Topic: Digital is the New Normal: The Role of Digital Media during the COVID-19 Crisis

25 Experts View on Digital Media in Times COVID-19

27 Provision of Remote Psychotherapy during the COVID-19 Pandemic

Elke Humer \& Thomas Probst

32 Teletherapy for Adolescent Psychiatric Outpatients: The Soaring Flight of so far Idle Technologies during the COVID-19 Pandemic

Mercedes M. Huscsava, Paul L. Plener \&

Oswald D. Kothgassner

36 Social Media as a Vehicle for Conspiracy Beliefs about COVID-19

Andreas Goreis \& Oswald D. Kothgassner

40 On the Need for Digital Phenotyping to Obtain Insights into Mental States in the COVID-19 Pandemic Christian Montag, Paul Dagum \& Jon D. Elhai 
als (RCTs), a lack of studies on non-drug interventions such as quarantines (despite them being one of the primary virus control methods), a rise in papers with limited generalizability (Abbas \& Pittet, 2020), and a profusion of duplicate publications, e.g., systematic reviews occurring in parallel (Glasziou, Sanders, \& Hoffmann, 2020).

Exclusivity, in turn, manifests itself in the shift of focus - as it may seem, almost entirely - to COVID-19-related research, for which an astonishing number of funding opportunities have been created, not only by governmental agencies but also by universities themselves (Omary et al., 2020). In some cases, universities, such as the one cited by Omary et al. (2020), are reported to have instituted policies drastically limiting non-critical research. Generally, as a consequence of different measures (hygiene related, lockdowns etc.), scientists are unable to carry out their experiments, and a considerable number report that they have lost some of their work (Korbel \& Stegle, 2020). In particular, young scientists with children as well as those relying on in-person (face-to-face)-contacts for their experiments are disproportionately affected (e.g., Myers et al., 2020).

Overall, the impact of the currently expedited speed and exclusivity is likely to be substantial, not only on scientists but on the science system itself. This may include funding agencies who might decide to primarily support those projects which are more durable in the face of restrictions like those experienced recently (Myers et al., 2020). Or it may involve even more subtle forms of constraints concerning the publication process, governance, and media coverage. Hence, following Ludwik Fleck that »once a structurally complete and closed system of opinions consisting of many details and relations has been formed, it offers enduring resistance to anything that contradicts it « (1979 [1935], p. 27), we can only affirm that the novel Journal Digital Psychology is dedicated to promoting plurality in the sense of a diverse, differentiated discourse, and that it will try its best to keep a thematic balance, remembering also - wherever possible - to tread the side paths.

Anna Felnhofer and Oswald D. Kothgassner

Editors-in-Chief

\section{References}

Abbas, M., \& Pittet, D. (2020). Surfing the COVID-19 scientific wave. The Lancet. Infectious Diseases.

Estrada, J. L. N. (2020). Science Under Stress. The Pandemic Effects on Research. Revista Argentina de Cardiología, 88(3), 191-193.

Fleck, L. (1979 [1935]). Genesis and Development of a Scientific Fact. Chicago: University of Chicago Press. [Entstehung und Entwicklung einer wissenschaftlichen Tatsache. Einführung in die Lehre vom Denkstil und Denkkollektiv. Basel: Schwabe und Co.]

Glasziou, P. P., Sanders, S., \& Hoffmann, T. (2020). Waste in covid-19 research. $B M J, 369$.

Korbel, J. O., \& Stegle, O. (2020). Effects of the COVID-19 pandemic on life scientists. Genome Biology, 21 (113).

Myers, K. R., Tham, W. Y., Yin, Y., Cohodes, N., Thursby, J. G., Thursby, M. C., ... \& Wang, D. (2020). Unequal effects of the COVID-19 pandemic on scientists. Nature Human Behaviour, 4, 880-883.

Omary, M. B., Eswaraka, J., Kimball, S. D., Moghe, P. V., Panettieri, R. A., \& Scotto, K. W. (2020). The COVID-19 pandemic and research shutdown: staying safe and productive. The Journal of clinical investigation, 130(6), 2745-2748. 